\title{
Triterpenic Acids and Flavonoids from Satureja parvifolia. Evaluation of their Antiprotozoal Activity
}

\author{
Catalina van Baren ${ }^{a}$, Ivie Anao ${ }^{b}$, Paola Di Leo Lira ${ }^{a}$, Silvia Debenedettic, \\ Peter Houghton ${ }^{\mathrm{b}}$, Simon Croft ${ }^{\mathrm{d}}$, and Virginia Martino ${ }^{\mathrm{a},{ }^{*}}$ \\ a Cátedra de Farmacognosia, Instituto de Química y Metabolismo del Fármaco IQUIMEFA \\ (UBA-CONICET), Facultad de Farmacia y Bioquímica, Universidad de Buenos Aires, \\ Junín 956, 1113 Buenos Aires, República Argentina. \\ Fax: 54 (11) 4508-3642. E-mail: vmartino@ffyb.uba.ar \\ b Department of Pharmacy, King's College London, Franklin-Wilkins Building, \\ 150 Stamford Street, London SEI 8WA, UK \\ c Cátedra de Farmacognosia, Facultad de Ciencias Exactas y Naturales, \\ Universidad Nacional de La Plata, calle 47 y 115, 1900 La Plata, República Argentina \\ d Parasitology Department, London School of Hygiene and Tropical Medicine, \\ Keppel Street, London WC1, UK \\ * Author for correspondence and reprint requests \\ Z. Naturforsch. 61c, $189-192$ (2006); received September 29, 2005
}

Bioassay-guided fractionation of a Satureja parvifolia $\mathrm{MeOH}$ extract led to the isolation of eriodictyol, luteolin and ursolic and oleanolic acids as its active components against Plasmodium falciparum $\mathrm{K} 1$. This is the first time these compounds are reported as constituents of $S$. parvifolia. Ursolic acid showed an $\mathrm{IC}_{50}$ of $4.9 \mu \mathrm{g} / \mathrm{m} \mathrm{l}$. luteolin $6.4 \mu \mathrm{g} / \mathrm{ml}$. oleanolic acid $9.3 \mu \mathrm{g} / \mathrm{ml}$ and eriodictyol $17.2 \mu \mathrm{g} / \mathrm{ml}$. Antiplasmodial activity of eriodictyol and luteolin is reported here for the first time.

Besides, the four compounds showed activity against $P$. falciparum 3D7 strain and Trypanosoma brucei rhodesiense. Eriodictyol showed moderate activity on all the parasites but was the most selective compound as a result of its rather low cytotoxicity $\left(\mathrm{IC}_{50} 174.2 \mu \mathrm{g} / \mathrm{ml}\right)$ on the mammalian KB cell line.

Key words: Satureja parvifolia, Antiprotozoal Compounds

\section{Introduction}

Satureja parvifolia (Philippi) Epling (Lamiaceae) grows at the verge of rivers descending from the hills in the northwestern provinces of Argentina (Salta, Jujuy, Córdoba, Catamarca, Tucumán) and is known with the common name of "muñamuña". Its traditional uses are as digestive, emmenagogue, aphrodisiac (Bandoni et al., 1972) and against altitude sickness (Orfila, 1972). Previous investigations on this plant deal with the chemical composition and the antifungal activity of its essential oil (Zygadlo and Grosso, 1995; Muschietti et al., 1996; Viturro et al., 2000). The brine shrimp cytotoxicity (Mongelli et al., 1996), smooth muscle relaxant activity on the Guinea pig corpus cavernosum (Hnatyszyn et al., 2003) and antimicrobial activity have been reported for $S$. parvifolia extracts (Hernández et al., 2000).

In the course of an ongoing screening of Argentine medicinal plants for antiplasmodial activity, $\mathrm{MeOH}$ and water extracts of $S$. parvifolia leaves showed significant activity against Plasmodium falciparum $\mathrm{K} 1$ with $\mathrm{IC}_{50}$ of 3 and $8.5 \mu \mathrm{g} / \mathrm{ml}$, respectively (Debenedetti et al., 2002). Bioassay-guided fractionation of the $\mathrm{MeOH}$ extract was encouraged in the search for the bioactive compounds. The ability to inhibit Plasmodium falciparum 3D7, a chloroquine sensitive strain, and Trypanosoma brucei rhodesiense was further tested for the isolated compounds.

\section{Material and Methods}

\section{Plant material}

The aerial parts of S. parvifolia were collected in Camino al Infiernillo, km 77, Tucumán Province, Argentina, in December 2002. A voucher specimen (A. Slanis 551) is kept at Instituto Miguel Lillo Herbarium, Tucumán, Argentina.

\section{Extraction and isolation}

The active $\mathrm{MeOH}$ extract was obtained as reported by Debenedetti et al. (2002) and fractionated by column chromatography (CC) on Se- 
phadex LH20 eluted with $\mathrm{MeOH}$. Seven fractions were obtained. Fractions 3 and 4 (F3, F4) proved to be the most active ones in the antiplasmodial assay. F3 was submitted to CC on Sephadex LH20 eluted with a solvent gradient from 100\% EtOAc to $100 \% \mathrm{MeOH}$. Eleven fractions were obtained. Fractions F5 to F7 were purified by paper chromatography (PC) in $40 \%$ AcOH. Two bands were eluted. F4 was submitted to $\mathrm{CC}$ using the same gradient as described for F3. A white amorphous powder precipitated from fractions F7 to F8. This was analyzed by GC-MS.

\section{GC-MS analysis}

GC-MS analysis was performed on a Perkin Elmer Clarus 500 GC-FID-MS instrument using a DB-5 fused-silica column $(60 \mathrm{~m} \times 0.25 \mathrm{~mm}$, film thickness $0.25 \mu \mathrm{m}$; J\&W Scientific Inc.); injector (split) temperature: $300^{\circ} \mathrm{C}$; splitting ratio: 1:60; oven temperature: $300{ }^{\circ} \mathrm{C}$ (isothermic); He: $1.8 \mathrm{ml} /$ min. Using a vent system (MSVent ${ }^{\mathrm{TM}}$ ) at the end of the column the flow was splitted into two detectors: a) FID detector maintained at $310^{\circ} \mathrm{C}$; b) MS quadrupolar detector $(70 \mathrm{eV})$. Transfer line temperature: $180^{\circ} \mathrm{C}$; source temperature: $150^{\circ} \mathrm{C}$; scan range: $40-600 \mathrm{Da}$.

\section{Antiplasmodial assay}

Antiplasmodial assay technique was performed as described in a previous paper (Debenedetti et al., 2002), measuring the uptake of [3H]-hypoxanthine by $P$. falciparum. The initial concentration of the fractions was $8 \mathrm{mg} / \mathrm{ml}$ diluted in medium to give a final concentration of $40 \mu \mathrm{g} / \mathrm{ml}$. The percentage growth inhibition on Plasmodium falciparum $\mathrm{K} 1$ at this concentration was measured. Pure compounds and chloroquine (standard antiplasmodial drug) were dissolved in DMSO to give stock solutions of $20 \mathrm{mg} / \mathrm{ml}$ and diluted with culture medium to give final concentrations of 100 to $0.41 \mu \mathrm{g} / \mathrm{ml}$ against $\mathrm{K} 1$ (chloroquine-resistant strain), 60 to $0.25 \mu \mathrm{g} / \mathrm{ml}$ against 3D7 (chloroquinesensitive strain) and $30 \mu \mathrm{g} / \mathrm{ml}$ to $0.2 \mathrm{ng} / \mathrm{ml}$ for chloroquine against both strains of $P$. falciparum. Threefold serial dilutions of the test compounds were made and they were performed in triplicate. The highest content of DMSO in the assay was $0.5 \%$. Each experiment was repeated twice. Statistical analysis was done using the non-paired heteroscedastic Student's test.

\section{Trypanocidal assay}

In vitro cultivation of bloodstream trypomastigote forms of Trypanosoma brucei rhodesiense STIB 900 (susceptible to melarsoprol, pentamidine and suramin) and determination of the trypanocidal activity of the test compounds was carried out as described by Asres et al. (2001). Each assay was done in triplicate and repeated at least once. Test compounds and pentamidine (as a standard antitrypanosomal drug) were dissolved in DMSO to give stock solutions of $20 \mathrm{mg} / \mathrm{ml}$ and diluted with culture medium to give final concentrations of 60 to $0.25 \mu \mathrm{g} / \mathrm{ml}$ and $1 \mu \mathrm{g} / \mathrm{ml}$ to $5.6 \mathrm{pg} / \mathrm{ml}$, respectively. The highest content of DMSO in the assay was $0.3 \%$.

\section{Cytotoxicity assay}

The cytotoxic properties of the test compounds were determined as described by Asres et al. (2001). The mammalian oral epidermoid carcinoma cell line $\mathrm{KB}$ cultivated in vitro in $10 \%$ HIFCS in RPMI-1640 was used. Test compounds and podophyllotoxin (standard cytotoxic drug) were dissolved in DMSO to give stock solutions of $20 \mathrm{mg} / \mathrm{ml}$ and diluted with culture medium to give final concentrations of 300 to $0.3 \mu \mathrm{g} / \mathrm{ml}$ and 300 to $0.003 \mathrm{pg} / \mathrm{ml}$, respectively. The highest content of DMSO was $1.5 \%$.

\section{Results and Discussion}

The bioassay-guided fractionation of a Satureja parvifolia $\mathrm{MeOH}$ extract afforded two major active fractions (F3 and F4) which showed inhibition of Plasmodium falciparum K1 growth (Table I). Phytochemical examination of these two fractions resulted in the isolation of two flavonoid and two triterpenoid compounds.

Table I. $P$. falciparum K1 inhibition by fractions from Satureja parvifolia $\mathrm{MeOH}$ extract.

\begin{tabular}{cc}
\hline Fraction & \% Inhibition $[40, \mu \mathrm{g} / \mathrm{ml}]$ \\
\hline F 1 & 16 \\
F 2 & 1 \\
F 3 & 61 \\
F 4 & 63 \\
F 5 & 37 \\
F 6 & 22 \\
F 7 & 0 \\
$0.5 \%$ DMSO control & 0 \\
\hline
\end{tabular}


Luteolin and eriodictyol were isolated from F3. These compounds were also present in F4. They were identified by comparison of their spectroscopic data with literature values (Mabry et al., 1970; Gujer et al., 1986) and by co-chromatography with authentic samples. Ursolic and oleanolic acids were identified from F4 by GC-MS analysis. The retention times and mass spectra of their methyl derivatives were compared with those obtained with authentic samples. The four of them inhibited the growth of $P$. falciparum K1, a chloroquine-resistant strain, with $\mathrm{IC}_{50}$ values ranging from 4.9 to $17.2 \mu \mathrm{g} / \mathrm{ml}$. The isolated compounds were further tested for their ability to inhibit the in vitro growth of $P$. falciparum 3D7, a chloroquinesensitive strain, and against $T$. brucei rhodesiense. All compounds showed activity against this $P$. falciparum strain with $\mathrm{IC}_{50}$ values ranging from 6.3 to $34.5 \mu \mathrm{g} / \mathrm{ml}$ and against $T$. brucei rhodesiense $(1.5$ to $14.4 \mu \mathrm{g} / \mathrm{ml}$ ). Cytotoxicity on mammalian $\mathrm{KB}$ cell line for these compounds was also assessed in order to determine their selectivity against the parasites (Tables II and III).

It is worth to point out that eriodictyol showed rather weak cytotoxicity to $\mathrm{KB}$ cells $\left(\mathrm{IC}_{50}\right.$ $174.2 \mu \mathrm{g} / \mathrm{ml}$ ), whilst retaining its antiprotozoal activity, it showed a higher selectivity than luteolin for the parasite. Luteolin had been previously reported as cytotoxic to other cell lines (Galvez et al., 2003).
Trypanocidal activity for eriodictyol on T. brucei brucei (Salem and Werbovetz, 2005) and for this compound and luteolin on T. cruzi (Grael et al., 2000,2005 ) has already been reported. In our investigation, trypanocidal activity against $T$. brucei rhodesiense was also found for both compounds ( $\mathrm{IC}_{50} 14.4 \mu \mathrm{g} / \mathrm{ml}$ and $2.3 \mu \mathrm{g} / \mathrm{ml}$, respectively) thus broadening their antiparasitic activity spectra.

As results of the bioguided fractionation of the active extracts of many medicinal plants, ursolic and oleanolic acids have been repeatedly reported in the literature as the antiparasitic principles (Steele et al., 1999; Abe et al., 2002; Suksamrarn et al., 2003; Cunha et al., 2003; Taketa et al., 2004). The results obtained herein showed activity for these two compounds against both $P$. falciparum strains and against $T$. brucei rhodesiense, consistent with the data found in the literature.

In conclusion, four antiprotozoal compounds: ursolic and oleanolic acids, eriodictyol and luteolin have been isolated from the $\mathrm{MeOH}$ extract of S. parvifolia by bioassay-guided fractionation. To the best of our knowledge, their presence in this species and the antiplasmodial activity of eriodictyol and luteolin are reported here for the first time. Eriodictyol showed a high selectivity for the parasites. This facts makes it an interesting lead structure for the development of new antiparasitic drugs.

Table II. Antiprotozoal activity and cytotoxicity of ursolic acid, oleanolic acid and eriodictyol from Satureja parvifolia.

\begin{tabular}{|c|c|c|c|c|}
\hline \multirow[b]{2}{*}{ Test compound } & \multicolumn{4}{|c|}{$\mathrm{IC}_{50}[\mu \mathrm{g} / \mathrm{ml}]$ (average $\left.\pm \mathrm{std}\right)$} \\
\hline & P. falciparum $\mathrm{K} 1$ & P. falciparum 3D7 & T. brucei & Mammalian KB cell line \\
\hline Ursolic acid & $4.9 \pm 0.1$ & \pm 4.6 & \pm 0.7 & \pm 7.7 \\
\hline Oleanolic acid & $9.3 \pm 0.2$ & \pm 1.5 & \pm 0.2 & \pm 10.7 \\
\hline Eriodictyol & $17.2 \pm 0.5$ & \pm 1.7 & \pm 1.6 & \pm 18.1 \\
\hline Chloroquine & $0.17 \pm 0.01$ & $0.015 \pm 0.005$ & - & - \\
\hline Pentamidine & - & - & $0.0008 \pm 0.0002$ & - \\
\hline Podophyllotoxin & - & - & - & $0.001 \pm 0.001$ \\
\hline
\end{tabular}

Table III. Antiprotozoal activity and cytotoxicity of luteolin from Satureja parvifolia.

\begin{tabular}{|c|c|c|c|c|}
\hline \multirow[b]{2}{*}{ Test compound } & \multicolumn{4}{|c|}{$\mathrm{IC}_{50}[\mu \mathrm{g} / \mathrm{ml}]($ average $\pm \mathrm{std})$} \\
\hline & $P$. falciparum $\mathrm{K} 1$ & P. falciparum 3D7 & T. brucei & Mammalian KB cell line \\
\hline Luteolin & $6.4 \pm 0.2$ & \pm 0.8 & \pm 1.7 & \pm 1.0 \\
\hline Chloroquine & $0.09 \pm 0.06$ & $0.0075 \pm 0.0040$ & - & - \\
\hline Pentamidine & - & - & $0.0004 \pm 0.0001$ & - \\
\hline Podophyllotoxin & - & - & - & $0.010 \pm 0.001$ \\
\hline
\end{tabular}




\section{Acknowledgements}

This investigation was performed in the framework of a joint project between The Royal Society (United Kingdom) and Consejo Nacional de In- vestigaciones Científicas y Técnicas CONICET (Argentina) and is partially supported by grants UBA SECYT B051, B101 and PIP CONICET 0542 and 02419 . Ivie Anao was supported by the Ford Foundation.
Abe F., Yamauchi T., Nagao T., Kinjo J., Okabe H., and Akahane H. (2002), Ursolic acid as trypanocidal constituent in rosemary. Biol. Pharm. Bull. 25, 14851487.

Asres K., Bucar F., Knauder E., Yardley V., Kendrick H., and Croft S. (2001), In vitro antiprotozoal activity of extract and compounds from the stem bark of Combretum molle. Phytother. Res. 15, 613-617.

Bandoni A., Mendiondo M., Rondina R., and Coussio I. (1972), Survey of argentine medicinal plants. I. Folklore and phytochemical screening. Lloydia 3, 69-78.

Cunha W. R., Martins C., da Silva Ferreira D., Miller Crotti A. E., Peporine Lopes N., and Alburquerque S. (2003), In vitro trypanocidal activity of triterpenes from Miconia species. Planta Med. 69, 470-472.

Debenedetti S., Muschietti L., van Baren C., Clavin M., Broussalis A., Martino V., Houghton P., Warhurst D., and Steele J. (2002), In vitro antiplasmodial activity of Argentinian plants. J. Etnopharmacol. 80, 163-166.

Galvez M., Martin-Cordero C., Lopez-Lázaro M., Cortés F., and Ayuso M. J. (2003), Cytotoxic effect of Plantago spp. on cancer cell lines. J. Ethnopharmacol. 88, $125-130$.

Grael C. F. F., Vichnewski W., Petto de Souza G. E., Lopes J. L. C., Albuquerque S., and Cunha W. R. (2000), A study of the trypanocidal and analgesic properties from Lychnophora granmongolense (Duarte) Semir \& Leitấo Filho. Phytother. Res. 14, 203-206.

Grael C. F. F., Albuquerque S., and Lopes J. L. C. (2005), Chemical constituents of Lychnophora pohlii and trypanocidal activity of crude plant extracts and of isolated compounds. Fitoterapia 76, 73-82.

Gujer R., Magnolato D., and Self R. (1986), Glucosylated flavonoids and other phenolic compounds from Sorghum. Phytochemistry 25, 1431-1436.

Hernández N. E., Tereschuk M. L., and Abdala L. R. (2000), Antimicrobial activity of flavonoids in medicinal plants from Tafí del Valle (Tucumán, Argentina). J. Ethnopharmacol. 73, 317-322.

Hnatyszyn O., Moscatelli V., García J., Rondina R., Costa M., Arranz C., Balaszczuk A., Ferraro G., and Coussio
J. D. (2003), Argentinian plant extracts with relaxant effect on the smooth muscle of the corpus cavernosum of guinea pig. Phytomedicine 10, 669-674.

Mabry T. J., Markham K. R., and Tomas M. B. (1970), The Systematic Identification of Flavonoids. Springer Verlag, Heidelberg, pp. 95, 286.

Mongelli E., Martino V., Coussio J., and Ciccia G. (1996), Screening of Argentine medicinal plants using the brine shrimp microwell cytotoxicity assay. Int. J. Pharmacognosy 34, 249-254.

Muschietti L., van Baren C., Coussio J., Vila R., Clos M., Cañigueral S., and Adzet T. (1996), Chemical composition of the leaf oil of Satureja odora and Satureja parvifolia. J. Essent. Oil Res. 8, 681-684.

Orfila E. N. (1972), Las especies de la flora medicinal argentina conocidas por "Muña-muña". Rev. Farm. 114, $3-12$.

Salem M. M. and Werbovetz K. A. (2005), Antiprotozoal compounds from Psorothamnus polydenius. J. Nat. Prod. 68, 108-111.

Steele J. C., Warhurst D. C., Kirby G. C., and Simmonds M. S. J. (1999), In vitro and in vivo evaluation of betulinic acid as an antimalarial. Phytother. Res. 13, $115-$ 119.

Suksamrarn A., Tanachatchairatana T., and Kanokmedhakul S. (2003), Antiplasmodial triterpenes from twigs of Gardenia saxatilis. J. Ethnopharmacol. 88, $275-277$.

Taketa A. T., Gnoato S. C. B., Gosmann G., Pires V. S., Schenkel E. P., and Guillaume D. (2004), Triterpenoids from Brazilian Ilex species and their in vitro antitrypanosomal activity. J. Nat. Prod. 67, 1697-1700.

Viturro C., Molina A., Guy I., Charles B., Guinaudeaeu H., and Fournet A. (2000), Essential oils of Satureja boliviana and $S$. parvifolia growing in the region of Jujuy, Argentina. Flavour Fragr. J. 15, $377-382$.

Zygadlo J. and Grosso R. (1995), Comparative study of the antifungal activity of essential oils from aromatic plants growing wild in the central region of Argentina. Flavour Fragr. J. 10, 113-118. 